\title{
O TRIPS E OS ACORDOS ANTERIORES SOBRE A PROTEÇÃO DA PROPRIEDADE INTELECTUAL
}

\author{
Isabela Piacentini de Andrade ${ }^{1}$
}

\section{RESUMO}

Esse artigo compara o sistema do TRIPS ao sistema anterior de proteção dos direitos da propriedade intelectual baseado em convenções internacionais. Explica-se como o TRIPS foi elaborado com vistas a evitar conflitos com a legislação internacional prévia, atendendo ao mesmo tempo aos interesses comerciais que motivaram a sua inclusão nas negociações do GATT. Analisa-se também como no campo da aplicação prática o TRIPS mostra-se superior ao sistema prévio das convenções internacionais.

\section{ABSTRACT}

This article compares the TRIPS' system to the previous international system of protection of the intellectual property rights which was based on international conventions. It explains how the TRIPS was designed in a way to avoid conflicts with the previous international legislation, yet still meeting the commercial interests that motivated its inclusion at the GATT negotiations. It also analyses how the TRIPS provisions regarding its implementation are better than the existing solutions of the previous system.

Indicadores: PROPRIEDADE INTELECTUAL - TRIPS - CONVENÇÕES INTERNACIONAIS

\footnotetext{
${ }^{1}$ Graduada em Direito pela UFPR, mestre e doutoranda em Direito Internacional Público pela Universidade de Paris II.
}

Revista Brasileira de Direito Internacional, Curitiba, v.4, n.4, jul./dez.2006 


\section{INTRODUÇÃO}

O movimento de internacionalização de normas sobre a proteção da propriedade intelectual começou no final do século XIX, com o advento das Convenções de Paris e de Berna. $\mathrm{O}$ apogeu desse processo foi a conclusão do Acordo TRIPS, no âmbito da Organização Mundial do Comércio (OMC). O TRIPS foi a resultante da integração das normas já existentes sobre a propriedade intelectual ao comércio internacional. Para melhor compreender como isso se deu, é preciso retornar às negociações do Ciclo do Uruguai.

A Rodada do Uruguai é conhecida por ter introduzido no GATT novas questões que não eram originalmente de sua competência ${ }^{2}$, embora não sem enfrentar resistências. A introdução da propriedade intelectual ${ }^{3}$, em particular, suscitou um grande debate. A idéia foi lançada pelos Estados Unidos e ganhou a adesão dos europeus. Firmes na defesa de seus interesses comerciais, os EUA ameaçavam abandonar o multilateralismo se o tema não fosse integrado ao GATT. ${ }^{4}$ A multiplicação do tráfico de mercadorias de contrafação ou "piratas", nociva ao comércio internacional devido às perdas econômicas daí resultantes, era o motivo anunciado dessa inclusão. ${ }^{5}$ Mas, nos bastidores desta agenda, eram os interesses das indústrias farmacêuticas norte-americana e européia que estavam representados. ${ }^{6}$

A posição dos países desenvolvidos (PD) refletia o descontentamento de seus industriais, para os quais o regime internacional de então (as Convenções de Paris e de Berna) não protegia adequadamente os direitos da propriedade intelectual ${ }^{7}$. Buscava-se, assim, um mecanismo mais eficaz de

\footnotetext{
${ }^{2}$ Como investimentos, comércio de serviços, e a propriedade intelectual.

3 ZHANG lembra que a qualificação do tema como «novo " deve ser relativizada, pois já existiam tentativas anteriores de incumbir o GATT de negociar um acordo internacional contra a contrafação (ZHANG, S. De l'OMPI au GATT: la protection internationale des droits de la propriété intellectuelle. Paris: Litec, 1994, p. 205 e ss.)

${ }^{4} \mathrm{~V}$. ZHANG, S. De l'OMPI au GATT: la protection internationale des droits de la propriété intellectuelle. Paris: Litec, 1994, p. 205 e ss.

${ }^{5}$ V. ZHANG, S. De l'OMPI au GATT: la protection internationale des droits de la propriété intellectuelle. Paris: Litec, 1994, p. 191 e ss. e p. 269.

6 V. a respeito a obra de Meir Perez PUGATCH: The International Political Economy of Intellectual Property Rights. Cheltenham/ Northampton : Edward Elgar, 2004.

7 ZHANG, S. De l'OMPI au GATT: la protection internationale des droits de la propriété intellectuelle. Paris: Litec, 1994, p. 305.
}

Revista Brasileira de Direito Internacional, Curitiba, v.4, n.4, jul./dez.2006 
defesa destes direitos, e o multilateralismo do GATT mostrava-se vantajoso pois (i) a proteção seria estendida a níveis globais e (ii) seria possível utilizar seu mecanismo de solução de controvérsias para tornar esta proteção mais eficaz. $^{8}$

Politicamente, houve enorme pressão para que o tema entrasse na pauta de negociações. Os países em desenvolvimento (PED), invocando o papel e o mandato do GATT, questionavam a lógica da inclusão de tal matéria. A Organização Mundial para a Propriedade Intelectual (OMPI) seria para eles a organização instituída e competente para tratar da questão. Aspectos econômicos também motivavam a aversão do mundo em desenvolvimento à recepção do tema pelo GATT. Os PED resistiam a toda tentativa de elevar o nível de proteção dos direitos da propriedade intelectual acima do que era garantido por suas legislações internas, devido aos limites advindos do seu estágio de desenvolvimento. Eles propugnavam por uma relação harmoniosa entre a remuneração dos direitos da propriedade intelectual por um lado e, por outro, o interesse público e social dos países retardatários no aspecto do desenvolvimento econômico e técnico. Do seu ponto de vista, as propostas da Rodada pareciam beneficiar apenas os países desenvolvidos tecnologicamente. ${ }^{9}$

Mas suas resistências foram rebatidas com ameaças de retaliações comerciais pelos países desenvolvidos, e após grandes pressões os PED acabaram por aceitar a negociação de um acordo abrangente sobre a propriedade intelectual. ${ }^{10}$

Obteve-se assim sinal verde para as negociações, mas tecnicamente a abordagem da questão no GATT defrontava-se com uma dificuldade importante: já existiam acordos internacionais sobre a propriedade intelectual, e sua gestão era competência da OMPI. Criar um sistema paralelo de proteção

\footnotetext{
8 ZHANG, S. De l'OMPI au GATT: la protection internationale des droits de la propriété intellectuelle. Paris: Litec, 1994, p. 269.

9 ZHANG, S. De l'OMPI au GATT: la protection internationale des droits de la propriété intellectuelle. Paris: Litec, 1994, p. 308-309, 332.

10 PUGATCH, M. P. The International Political Economy of Intellectual Property Rights. Cheltenham/ Northampton : Edward Elgar, 2004, p. 129.
}

Revista Brasileira de Direito Internacional, Curitiba, v.4, n.4, jul./dez.2006 
no seio do GATT poderia gerar conflitos de interpretação de normas, além de problemas de coordenação de competências entre organizações.

Buscando evitar problemas, o TRIPS foi elaborado utilizando como base as convenções internacionais já existentes sobre a proteção da propriedade intelectual que gozavam de maior aceitação na comunidade internacional. O TRIPS assimila, assim, com algumas adaptações: a Convenção de Paris de 1967 para a Proteção da Propriedade Industrial ${ }^{11}$, a Convenção de Berna de 1971 para a Proteção de Obras Literárias e Artísticas $^{12}$, a Convenção de Roma de 1961 para a Proteção dos Artistas Intérpretes ou Executantes, dos Produtores de Fonogramas e dos Organismos de Radiodifusão, e o Tratado de Washington de 1989 sobre a Proteção da Propriedade Intelectual Relativa aos Circuitos Integrados.

No mesmo espírito conciliatório, o Acordo TRIPS estabelece que as disposições dos acordos anteriores não sofrem derrogação e que obrigações internacionais já contraídas pelos países signatários destes acordos são mantidas. Entretanto, algumas adaptações das normas existentes foram necessárias para ajustá-las à realidade comercial e às regras do GATT. ${ }^{13}$

Nasce assim o Acordo sobre os Aspectos dos Direitos de Propriedade Intelectual relacionados com o Comércio (TRIPS na sigla em inglês), anexo 1C do Acordo que criou a $\mathrm{OMC}^{14}$. Apesar do nome, o Acordo não se restringiu aos meros aspectos comerciais da propriedade intelectual, acabando por tratar desta em todos os seus detalhes.

O objetivo deste artigo é o de analisar as relações do TRIPS com os acordos anteriores sobre a proteção da propriedade intelectual, entendendo-o como o resultado da integração destes ao comércio internacional (parte 1). A segunda parte do artigo analisa a aplicação do TRIPS, tanto em nível interno como internacional. Em suma, o artigo faz uma comparação do sistema atual

\footnotetext{
${ }_{11}^{11}$ A Convenção de Paris foi assinada em 1883 e revisada pelo Ato de Estocolmo de 1967.

12 Convenção de Berna de 1886 revisada pelo Ato de Paris de 1971.

${ }^{13}$ V. CHRISTOFOROU, T. L'accord du Cycle d'Uruguay sur les droits de propriété intellectuelle qui touchent au commerce ("TRIPS"). In: FLORY, T. La Communauté européenne et le GATT: évaluation des accords du cycle d'Uruguay. Rennes: Editions Apogée, 1995, p. 144-145.

${ }^{14} \mathrm{O}$ Acordo Constitutivo da OMC foi assinado em abril de 1994 e entrou em vigor em janeiro de 1995.
}

Revista Brasileira de Direito Internacional, Curitiba, v.4, n.4, jul./dez.2006 
de proteção da propriedade intelectual (expresso no TRIPS) ao sistema anterior (convenções internacionais).

\section{A INTEGRAÇÃO DOS ACORDOS INTERNACIONAIS SOBRE A PROPRIEDADE INTELECTUAL AO COMÉRCIO INTERNACIONAL}

O desafio de integrar a legislação internacional existente sobre a propriedade intelectual ao GATT gerou duas sortes de adaptações. Por um lado, as normas do GATT foram flexibilizadas para acomodar as disposições dos acordos anteriores; por outro, estes acordos foram adaptados e incrementados para responder às exigências comerciais.

\subsection{A BUSCA DA COMPATIBILIDADE}

A feição do TRIPS foi determinada pela preocupação de não se opor a uma legislação sobre a propriedade intelectual já existente e largamente aceita pela comunidade estatal. Foi visando à harmonia entre o sistema anterior e o GATT, pois, que o TRIPS tomou como base as convenções sobre a propriedade intelectual já existentes, às quais ele remete expressamente. Assim, ao invés de reproduzir as disposições dos acordos anteriores, em vários momentos o GATT faz uma simples remissão a estes, operando-se uma verdadeira incorporação de regras.

Adicionalmente, o artigo 2.2 do Acordo dispõe que

\footnotetext{
"Nenhuma das disposições incluídas nas partes I a IV do presente Acordo poderá constituir uma derrogação das obrigações que possam vincular os Membros entre si em virtude da Convenção de Paris, da Convenção de Berna, da Convenção de Roma e do Tratado sobre a Proteção da Propriedade Intelectual Relativa aos Circuitos Integrados.”
}

Ou seja, se na ocasião da assinatura das Convenções citadas foram contraídas obrigações conflitantes com o TRIPS, este não as derrogará; as obrigações e reservas anteriormente acordadas continuam vigentes para os países signatários.

Revista Brasileira de Direito Internacional, Curitiba, v.4, n.4, jul./dez.2006 
A busca pela compatibilidade influenciou igualmente a integração dos dois princípios básicos do comércio internacional à propriedade intelectual. Com o advento do TRIPS, os princípios do tratamento nacional e da nação mais favorecida, regras norteadores do GATT, foram transpostos para o âmbito da propriedade intelectual. Entretanto, em respeito às obrigações preexistentes, eles foram relativizados. Como as obrigações e reservas decorrentes dos acordos anteriores continuam em vigor, esses princípios não são aplicados de forma absoluta no âmbito do TRIPS.

$\mathrm{O}$ artigo 3 do TRIPS dispõe que

\begin{abstract}
“Cada Membro concederá aos nacionais de outros Membros um tratamento não menos favorável do que o que concede aos seus próprios nacionais no que se refere à proteção da propriedade intelectual, sem prejuízo das exceções já previstas, respectivamente na Convenção de Paris (1967), na Convenção de Berna (1971), na Convenção de Roma ou no Tratado sobre a Proteção da Propriedade Intelectual Relativa aos Circuitos Integrados (...)”
\end{abstract}

Enuncia-se aí o princípio do tratamento nacional, segundo o qual os Estados se comprometem a conferir a nacionais de outros Estados o mesmo tratamento que eles conferem aos próprios nacionais. Mas em seguida já se assinala que as obrigações anteriorermente contraídas excepcionam sua aplicação.

Tal princípio não era uma novidade na regulamentação internacional da propriedade intelectual. $\mathrm{Na}$ verdade, o tratamento nacional era a base da proteção conferida pelas convenções internacionais. Entretanto, como assinala CHRISTOFOROU, o regime dos acordos anteriores aplicava-o apenas à proteção dos direitos de propriedade intelectual, e não ao seu exercício. No texto do TRIPS, o termo "proteção" possui um alcance maior pois visa-se igualmente ao exercício dos direitos pelos estrangeiros. ${ }^{15}$ Sob a base da reciprocidade, alguns signatários afastavam a aplicação do princípio ao assinar

\footnotetext{
${ }^{15}$ CHRISTOFOROU, T. L'accord du Cycle d'Uruguay sur les droits de propriété intellectuelle qui touchent au commerce ("TRIPS"). In: FLORY, T. La Communauté européenne et le GATT: évaluation des accords du cycle d'Uruguay. Rennes: Editions Apogée, 1995, p. 146-147. A nota 3 enuncia que "Para efeitos do disposto nos artigos $3^{\circ}$. e $4^{\circ}$., o termo "proteção" abrange as questões relativas à existência, aquisição, âmbito, manutenção e aplicação efetiva dos direitos de propriedade intelectual, bem como as questões relativas ao exercício dos direitos de propriedade intelectual, expressamente contempladas no presente acordo.
}

Revista Brasileira de Direito Internacional, Curitiba, v.4, n.4, jul./dez.2006 
os acordos anteriores; tais reservas continuam em vigor conforme dispõe o artigo 3.

O princípio da nação mais favorecida, diferentemente do tratamento nacional, é novidade no âmbito da propriedade intelectual. Sua aplicação objetiva sobretudo impedir que se produzam discriminações de tratamento advindas da conclusão de acordos bilaterais. Nesse sentido, o artigo 4 do TRIPS enuncia que

\footnotetext{
"No que diz respeito à proteção da proriedade intelectual, todas as vantagens, favores, privilégios ou imunidades concedidos por um Membro aos nacionais de qualquer outro país serão concedidos, imediata e incondicionalmente, aos nacionais de todos os outros Membros (...)".
}

Exceções à regra foram igualmente previstas para preservar ajustes interestatais prévios.

\subsection{UMA PROTEÇÃO REFORÇADA}

Apesar das concessões ao sistema anterior, os interesses que motivaram a entrada da propriedade intelectual no seio do comércio não poderiam ser esquecidos. O objetivo era o de reforçar e ampliar a proteção dos direitos da propriedade intelectual em escala global. É assim que no seu primeiro artigo, o Acordo TRIPS determina que os Estados devem dar efeito às disposições que ele estipula, mas confere igualmente aos Membros a faculdade de adotar uma proteção dos direitos da propriedade intelectual mais ampla do que a prevista pelo Acordo. O TRIPS constitui portanto a expressão dos standards mínimos de proteção que são exigidos dos Estados, os quais podem ser enriquecidos pelas legislações nacionais. Essa disposição, segundo o que afirma ZHANG, foi uma resposta às preocupações dos países desenvolvidos, os quais temiam que as negociações do TRIPS poderiam culminar num nível inferior de proteção dos direitos da propriedade intelectual. $^{16}$

\footnotetext{
${ }^{16}$ ZHANG, S. De l'OMPI au GATT: la protection internationale des droits de la propriété intellectuelle. Paris: Litec, 1994, p. 321-322.
}

Revista Brasileira de Direito Internacional, Curitiba, v.4, n.4, jul./dez.2006 
Além disso, é notório que o TRIPS estipulou padrões superiores de proteção nos vários campos da propriedade intelectual. $\mathrm{O}$ direito herdado das convenções preexistentes constituiu a base do TRIPS, mas adicionalmente estipularam-se novas obrigações, que alguns denominam de os "elementos plus". ${ }^{17}$

De fato, o TRIPS estabeleceu um "plus" de proteção para cada um dos direitos da propriedade intelectual: direitos do autor e direitos conexos, marcas, indicações geográficas, desenhos e modelos industriais, patentes, configurações (topografias) de circuitos integrados e proteção de informações não divulgadas.

$\mathrm{Na}$ esfera dos direitos do autor e conexos, o TRIPS adotou essencialmente as regras da Convenção de Berna - o artigo 9.1. do TRIPS remete aos artigos $1^{\circ}$. à 21 da Convenção -, mas previu uma proteção mais abrangente em alguns aspectos. Tal é o caso para os programas de computador, que passam a ser protegidos como obras literárias; do direito de locação exclusivo que é conferido aos autores de programas informáticos e de obras cinematográficas; e dos artistas intérpretes ou executantes e produtores, que recebem uma proteção mais abrangente e aumentada para 50 anos. Em contrapartida, o TRIPS não contemplou a proteção aos direitos morais, cedendo a resistências norte-americanas.

As disposições existentes sobre marcas foram consideravelmente revisadas pelo TRIPS. As normas gerais foram inspiradas na Convenção de Paris, mas a estas o Acordo adicionou outras como a previsão de uma estrita igualdade de proteção entre marcas de produtos e marcas de serviços. As marcas notórias foram objeto de atenção especial, sua proteção foi reforçada.

As indicações geográficas receberam melhor acolhida no TRIPS, contrastando com o tratamento minoritário que tinham na Convenção de Paris. Tal consideração deveu-se a pressões dos europeus durante as negociações, interessados sobretudo na proteção da indicação de origem dos seus vinhos e bebidas alcoólicas.

\footnotetext{
${ }^{17}$ CARREAU, D. e JUILLARD, P. Droit international économique, 2a. ed. Paris: Dalloz, 2005, p. 325.
}

Revista Brasileira de Direito Internacional, Curitiba, v.4, n.4, jul./dez.2006 
Também no tocante aos desenhos e modelos industriais, o TRIPS ultrapassa o nível de proteção previsto até então em nível internacional. 0 artigo 5 da Convenção de Paris previa simplesmente que "os desenhos e modelos industriais serão protegidos". Os artigos 25 e 26 do TRIPS são mais detalhistas e fixam alguns parâmetros a serem respeitados, apesar de deixarem uma grande liberdade aos Membros para elaborar a legislação interna a respeito.

Igualmente em matéria de patentes o TRIPS estabelece uma normativa mais completa que a da Convenção de Paris. É importante assinalar que as negociações sobre patentes foram as mais acaloradas do TRIPS, dada a importância econômica e política da questão. Os PD representavam claramente os interesses de suas multinacionais, sobretudo da área farmacêutica, revelando uma visão monopolística da patente, centrada nos interesses dos seus titulares. Já os PED, defendendo os benefícios coletivos da invenção, contestavam os benefícios que a proteção patentária traria, principalmente no campo farmacêutico. ${ }^{18} \mathrm{O}$ TRIPS alargou as hipóteses de patenteabilidade, possibilitando uma proteção generalizada dos medicamentos. Mas devido às resistências dos PED, tal reforço de proteção teve que ser sujeito à exceções, como no caso da licença compulsória para casos extremos como imperativos de saúde pública. A utilização das exceções é objeto de grandes conflitos, como revelaram os debates sobre os farmacêuticos diante dos problemas que enfrentam muitos países subdesenvolvidos devido a doenças como a AIDS.

Finalmente, para as topografias de circuitos integrados, o TRIPS remete ao Tratado internacional sobre a questão, acrescentando apenas algumas disposições adicionais.

Em resumo, pode-se dizer que a integração pelo TRIPS dos acordos anteriores sobre a propriedade intelectual, somada às novas regras criadas,

\footnotetext{
${ }^{18}$ Ver ZHANG, S. De l'OMPI au GATT: la protection internationale des droits de la propriété intellectuelle. Paris: Litec, 1994, p. 340 ss. e REMICHE, B. e DESTERBECQ, H. Les brevets pharmaceutiques dans les accords du GATT: l'enjeu?, Revue internationale de droit économique, 1996, vol. 10, p. 7-68.
}

Revista Brasileira de Direito Internacional, Curitiba, v.4, n.4, jul./dez.2006 
resultaram num reforço geral da proteção da propriedade intelectual em nível mundial.

Cabe agora analisar a aplicação do Acordo, a fim de estabelecer uma comparação entre a prática do sistema anterior e o atual.

\section{A APLICAÇÃO DO ACORDO TRIPS}

Uma das principais críticas que se fazia ao sistema anterior de proteção da propriedade intelectual dizia respeito à deficiência dos meios para a sua colocação em prática. O TRIPS evolui consideravelmente nesse aspecto, estabelecendo mecanismos mais eficazes de controle tanto no plano interno como no plano internacional.

\subsection{NO PLANO INTERNO}

O resultado evidente da incorporação das convenções internacionais pelo TRIPS é a aplicação ampliada de suas disposições. Se antes apenas os signatários de cada acordo internacional tinham o dever a respeitá-lo, agora todas as normas incorporadas e reforçadas pelo TRIPS passam a ser obrigatórias para todos os Membros da OMC. Em conseqüência, há um aumento geral do nível de proteção em escala mundial, e uma harmonização desta proteção. Os titulares dos direitos de propriedade intelectual podem usufruir destes em qualquer Membro da OMC, não sofrendo mais as diferenças de nível de proteção segundo o país.

O TRIPS estabelece um grande rol de medidas a serem tomadas pelos Estados Membros para transpôr as exigências do TRIPS para a esfera nacional. Para garantir o exercício dos direitos pelos titulares, o TRIPS exige que sejam criados procedimentos administrativos ou judiciais, os quais devem obedecer às regras fundamentais do Estado de direito (contraditório, decisões motivadas, revisão das decisões, etc. $)^{19}$ As medidas e processos devem ser ágeis, leais, eqüitativos e simples, e não devem constituir um obstáculo ao

${ }^{19}$ DAILLIER, P., LA PRADELLE, G. E GHERARI, H. Droit de l'économie internationale. Paris: Pedone, 2004, p. 466.

Revista Brasileira de Direito Internacional, Curitiba, v.4, n.4, jul./dez.2006 
comércio. Medidas temporárias podem ser adotadas para impedir a violação dos direitos da propriedade intelectual e preservar elementos de prova.

Toda uma seção é dedicada a medidas que podem ser tomadas na fronteira, focando sobretudo na captura de mercadorias pirateadas ou contrafeitas. O TRIPS determina também que os Membros devem prever processos penais e penas para atos que violam de forma grave os direitos da propriedade intelectual.

Assim, um conjunto de regras em prol do exercício efetivo dos direitos da propriedade intelectual é estabelecido. Os Membros da OMC devem concretizar as determinações do TRIPS no seu ordenamento interno, mas o Acordo deixa aos países a liberdade de fazê-lo segundo o método que eles julguem mais apropriado, segundo seus próprios sistemas jurídicos e práticas nacionais. Os prazos de aplicação do Acordo na esfera interna foram escalonados segundo o nível de desenvolvimento dos países, dadas as disparidades tecnológicas e legislativas entre os Membros.

\subsection{NO PLANO INTERNACIONAL}

No plano internacional, a aplicação do TRIPS é exercida por dois órgãos da OMC: o Conselho TRIPS e o Órgão de Solução de Controvérsias (OSC).

O Conselho TRIPS foi criado para acompanhar o funcionamento do Acordo e verificar se os Membros cumprem as obrigações por ele estipuladas. Tal Conselho, do qual fazem parte todos os Membros da OMC, deve portanto supervisionar as adaptações legislativas realizadas pelos Estados Membros, dentro dos prazos previstos. Além disso, o Conselho deve prestar assitência aos países que queiram fazer consultas sobre questões relativas ao Acordo, e se solicitado fornecer auxílio para a resolução de litígios.

É de se indagar o papel da OMPI dentro desse novo contexto. O TRIPS assinala que "em consulta com a OMPI, o Conselho procurará estabelecer, no prazo de um ano a contar da sua primeira reunião, disposições adequadas relativamente à cooperação com os órgãos dessa organização". 
Em 1995, foi assinado um acordo de cooperação entre as organizações. Mas na prática, a OMPI não exerce uma função substancial dentro do novo contexto trazido pelo TRIPS à propriedade intelectual, confirmando o receio que muitos países manifestaram durante as negociações. Em razão do seu aspecto político, o Conselho TRIPS parece exercer um papel mais significativo do que aquele exercido pela OMPI; tal organização afigura-se fragilizada depois do advento do Acordo e suas atividades acabam limitando-se cada vez mais a funções técnicas.

Eventuais litígios que surjam em relação ao Acordo podem ser submetidos aos sistema de solução de controvérsias da OMC. Trata-se de uma vantagem considerável em comparação às possibilidades de resolução de litígios interestatais previstas nos acordos anteriores sobre a propriedade intelectual. As Convenções de Paris e de Berna previam que em caso de conflito, a Corte Internacional de Justiça (CIJ) poderia ser acionada unilateralmente. Entretanto, tal disposição poderia ser objeto de reserva por parte dos signatários. Na prática, aparentemente nunca se utilizou a ClJ sob o fundamento dessas Convenções.

As vantagens anunciadas do mecanismo de solução de controvérsias da OMC seriam sobretudo sua eficácia, rapidez e previsibilidade. A doutrina assinala também a possibilidade das represálias cruzadas como particularmente interessante para os direitos da propriedade intelectual, já que estes são direitos privados e é portanto difícil imaginar a aplicação de contramedidas na mesma área.

A incorporação das convenções internacionais pelo TRIPS e sua interpretação pelo OSC não é isenta de importantes conseqüências, como lembra BERGE: "ao incorporar as disposições desses tratados internacionais, o Acordo TRIPS apropria-se delas. A interpretação e a aplicação dessas disposições obedecem às regras da $\mathrm{OMC}$, notadamente procedimentais, que não têm estritamente nada a ver com o que poderia ser proposto no seio da 
OMPI. ${ }^{20}$ A gestão dos acordos anteriores pela OMPI, portanto, poderia ser afetada, assim como seu papel na elaboração de futuras convenções.

Independentemente disso, dada a sua riqueza normativa e seus mecanismos de aplicação, o TRIPS é amplamente reconhecido como sendo um sistema de proteção dos direitos de propriedade intelectual superior ao sistema das convenções anteriores. Nessa linha, CARREAU afirma que

“o TRIPS aparece assim como o primeiro (e atualmente o único) tratado abrangendo todos os elementos constitutivos da propriedade intelectual e dotando-lhes de um regime jurídico internacional mínimo de proteção dotado de meios eficazes tanto nacionais como internacionais para assegurar seu cumprimento., 21

\section{CONCLUSÃO}

Em termos gerais, o TRIPS representa um grande reforço da proteção dos direitos de propriedade intelectual. Primeiramente, por ter estabelecido materialmente uma proteção reforçada, através do conteúdo do seu texto. E em segundo lugar, por ter ampliado consideravelmente o nível de aplicação desta proteção entre os países: hoje todos os membros da OMC devem submeter-se aos dispositivos do TRIPS; antes a adesão aos tratados setoriais de propriedade intelectual era feita de forma dispersa. No momento atual, 150 Estados $^{22}$ são obrigados a respeitar uma ampla gama de direitos da propriedade intelectual, que vão desde os reconhecidos direitos autorais e de propriedade industrial aos novos direitos criados pelas novas tecnologias. Tal panorama difere substancialmente daquele existente anteriormente ao TRIPS, segundo o qual cada convenção internacional tratava de um aspecto específico da propriedade intelectual, e a adesão estatal era difusa.

Outro avanço da TRIPS foi o de determinar que os Estados devem realizar modificações legislativas internas e adotar medidas executórias específicas para dar aplicação ao TRIPS. Tal obrigação, inexistente ou ao

${ }^{20}$ DAILLIER, P., LA PRADELLE, G. E GHERARI, H. Droit de l'économie internationale. Paris: Pedone, 2004, p. 454.

${ }^{21}$ CARREAU, D. e JUILLARD, P. Droit international économique, 2a. ed. Paris: Dalloz, 2005, p. 323.

${ }^{22}$ Número de membros da OMC em 11 de janeiro de 2007.

Revista Brasileira de Direito Internacional, Curitiba, v.4, n.4, jul./dez.2006 
menos minoritária anteriormente, conduz a uma harmonização das normas de propriedade intelectual e possibilita o seu exercício em escala planetária.

Tais aportes são indubitavelmente vantajosos para os titulares dos direitos de propriedade intelectual: autores, inventores, artistas... Mas é importante notar que a grande maioria da propriedade intelectual produzida no mundo é proveniente dos países desenvolvidos, que a exportam para os consumidores do Sul: os países em desenvolvimento ou menos avançados. $E$ o sistema do TRIPS foi claramente construído para proteger os interesses apenas dos primeiros, detentores de conhecimento.

Uma análise mais ampla conduz ao questionamento dos benefícios que esta proteção acentuada pode trazer para o livre comércio internacional e para a sociedade. Ao conceder o monopólio de exploração da obra ao titular do direito de propriedade intelectual, cria-se uma certa contradição com o objetivo de liberalização comercial, que é o de criar concorrência e liberalizar as trocas. A lógica da proteção da propriedade intelectual também é de certa forma desfavorável do ponto de vista social: se por um lado seu objetivo é incentivar a produção intelectual no futuro, por outro ela restringe a difusão livre de conhecimentos no presente. ${ }^{23} \mathrm{E}$ em conseqüência os países do Sul sofrerão sempre um atraso de no mínimo 20 anos em termos de tecnologia, precisando assim sempre importar devido à sua incapacidade de produzir internamente.

Em algumas situações, o prejuízo para a sociedade é patente. Tal é o caso dos medicamentos. Uma proteção rígida da indústria farmacêutica contrasta com as necessidades urgentes da saúde pública, como é o caso dos medicamentos para a AIDS. As conquistas da indústria farmacêutica foram notáveis nesse domínio, mas felizmente tiveram recentemente que ceder a imperativos humanos devido a pressões dos países em desenvolvimento. Estes parecem ser os maiores prejudicados com o sistema do TRIPS. O déficit intelectual-tecnológico do Sul em relação ao Norte não é novidade, e o TRIPS foi desenhado para manter esse status quo. Os interesses dos países em desenvolvimento parecem ainda mais flagrantemente negligenciados quando se constata que o TRIPS ignorou a proteção dos conhecimentos tradicionais, ${ }^{23}$ PUGATCH, Meir Perez. The International Political Economy of Intellectual Property Rights.
Cheltenham/ Northampton : Edward Elgar, 2004, p. ix.

Revista Brasileira de Direito Internacional, Curitiba, v.4, n.4, jul./dez.2006 
oriundos na sua maioria de populações autóctones dos países em desenvolvimento. Empresas inescrupulosas aproveitam-se desta ausência de regulamentação para se apoderar das técnicas milenares dos índios da Amazônia e patenteá-las, tornando-se assim titular da "criação" e podendo explorá-la economicamente em caráter monopolístico.

Portanto, apesar de afirmarmos que o TRIPS representou um avanço considerável em relação ao sistema anterior de proteção da propriedade intelectual, é preciso que se saiba que há ganhadores e perdedores com o novo sistema, que não leva adequadamente em consideração as diferenças de desenvolvimento entre os países. Os direitos da propriedade intelectual estão certamente melhor protegidos, mas o benefício social daí decorrente é duvidoso.

\section{REFERÊNCIAS}

CARREAU, D. e JUILLARD, P. Droit international économique, 2a. ed. Paris: Dalloz, 2005.

CHRISTOFOROU, T. L'accord du Cycle d'Uruguay sur les droits de propriété intellectuelle qui touchent au commerce ("TRIPS"). In: FLORY, T. La Communauté européenne et le GATT: évaluation des accords du cycle d'Uruguay. Rennes: Editions Apogée, 1995, p. 141-162.

DAILLIER, P., LA PRADELLE, G. e GHERARI, H. Droit de l'économie internationale. Paris: Pedone, 2004.

REMICHE, B. e DESTERBECQ, H. Les brevets pharmaceutiques dans les accords du GATT: I'enjeu?, Revue internationale de droit économique, 1996, vol. 10, p. 7-68.

PUGATCH, Meir Perez. The International Political Economy of Intellectual Property Rights. Cheltenham/ Northampton : Edward Elgar, 2004.

ZHANG, S. De I'OMPI au GATT: la protection internationale des droits de la propriété intellectuelle. Paris: Litec, 1994. 